\title{
Pengaruh Kepemimpinan Transformasional Terhadap Kinerja Karyawan Yang Dimediasi Oleh Kepercayaan Organisasional dan Komitmen Afektif di PT Arpeni Pratama Ocean Line Tbk. Cabang Jepara
}

\author{
${ }^{1}$ Zandra Dwanita Widodo, ${ }^{2}$ Sri Wijiastuti, ${ }^{3}$ Kurniawari Darmaningrum \\ Universitas Tunas Pembangunan Surakarta, Jawa Tengah, Indonesia \\ Email : ${ }^{1}$ zandra.febutp@gmail.com
}

(Diterima: Juli 2021; Direvisi: Agustus 2021; Dipublikasikan: September 2021)

\begin{abstract}
ABSTRAK
Penelitian ini bertujuan untuk mengetahui pengaruh kepemimpinan transformasional terhadap kinerja karyawan yang dimediasi oleh kepercayaan organisasional dan komitmen afektif karyawan. Penelitian ini menggunakan desain survey, berjenis penelitian kausal, yaitu tipe penelitian yang bersifat konklusif yang bertujuan untuk menjelaskan hubungan antar variabel yang dibedakan menjadi variabel independen yang merupakan suatu penyebab dan variabel dependen yang merupakan akibat dari suatu fenomena. Sampel yang digunakan sebanyak 58 responden dengan pengambilan sampel dalam penelitian ini dilakukan dengan menggunakan metode sensus, dimana seluruh anggota populasi diambil sebagai responden penelitian (penelitian populasi). Temuan penelitian menunjukkan bahwa dari lima hipotesis yang diajukkan terdapat tiga hipotesis yang terbukti, yaitu hubungan kepemimpinan transformasional pada kepercayaan organisasi, hubungan kepercayaan organisasi pada komitmen afektif, dan hubungan komitmen afektif pada kinerja karyawan yang memiliki pengaruh signifikan. Dua hipotesis tidak terbukti yaitu hubungan kepemimpinan transformasional pada komitmen afektif dan hubungan keprecayaan organisasional pada kinerja yang memiliki pengaruh tidak signifikan. Hal ini menunjukkan bahwa kepemimpinan transformasional memiliki pengaruh pada kinerja setelah dimediasi oleh kepercayaan organisasional dan komitmen afektif (secara full mediasi).
\end{abstract}

Kata Kunci: GSCA, Kepemimpinan Transformasional, Kepercayaan Organisasional, Komitmen Afektif, dan Kinerja Karyawan 


\section{PENDAHULUAN}

Dalam perusahaan karyawan merupakan suatu aset yang sangat berharga yang harus dikelola dengan baik oleh perusahaan agar dapat memberikan kontribusi yang optimal. Salah satu hal yang harus menjadi perhatian utama perusahaan adalah kinerja para karyawannya, karena karyawan dalam pekerjaanya mereka tidak merasakan kenyamanan, kurang dihargai, tidak bisa mengembangkan segala potensi yang mereka miliki, maka secara otomatis karyawan tidak dapat fokus dan secara penuh dalam berkonsentrasi pekerjaannya. Keberhasilan suatu organisasi sangat bergantung pada bagaimana ia menarik/merekrut karayawan, memotivasi dan mempertahankan karyawan berkinerja tinggi. Menjelaskan faktor-faktor yang mempengaruhi kinerja karyawan tetap menjadi pertanyaan mendasar bagi praktisi manajemen sumber daya manusia. Teori harapan dari Vroom, Porter, dan Lawler, menegaskan bahwa kinerja karyawan tidak hanya bergantung pada jumlah usaha yang dilakukan, tetapi juga pada pengaruh faktor-faktor seperti kemampuan dan sifat seseorang, serta persepsi peran mereka. Periset juga menyarankan agar berbagai faktor organisasi dan karyawan dapat mempengaruhi kinerja karyawan (Muindi, dan K'Obonyo, 2015).

Karyawan merupakan sumber
daya berharga harus mampu
memberikan keunggulan kompetitif
bagi organisasi. Pandangan berbasis
sumber daya berpendapat bahwa
sumber daya manusia dapat
memenuhi kriteria sumber daya yang
berharga, langka, tidak ada
bandingannya, dan tidak dapat

diganti. Agar organisasi berhasil, ada kebutuhan untuk menjawab kebutuhan karyawan, terutama pada aspek seperti kualitas hidup kerja dan faktor lain yang dapat berdampak pada kinerja karyawan. Teori Lapangan Kurt Lewin tentang perilaku karyawan menggambarkan hubungan antara kualitas kehidupan kerja dan kinerja. Menurut teori ini, perilaku individu dipengaruhi oleh bagaimana seseorang memandang dan bereaksi terhadap lingkungan, yang dalam penelitian ini dianggap berarti kualitas lingkungan kerja. Dua faktor tersebut lebih jauh menunjukkan bahwa karakteristik individu (diwujudkan dalam kepribadian) dan persepsi lingkungan dapat mempengaruhi perilaku dan kinerja individu (Muindi, dan K'Obonyo, 2015).

Pemimpin merupakan bagian penting keefektifan organisasi dan pekerja. Pemimpin diharapkan dapat mengarahkan, mengembangkan dan tidak memasung kreativitas karyawan untuk mencapai tujuan-tujuan organisasi. Kebanyakan peneliti mengevaluasi efektifitas pemimpin terkait erat dengan konsekuensikonsekuensi tindakan pemimpin terhadap para pengikutnya dan para stakeholder dari organisasi lain, namun pilihan-pilihan variabel keluaran (outcome) cukup berbeda dari seorangPeneliti satu dengan peneliti yang lainnya. Sebagaimana dikutip oleh Rivai (2004), Katz \& Kahn mengatakan bahwa "Kepemimpinan adalah peningkatan pengaruh sedikit demi sedikit pada karyawan, dan berada di atas kepatuhan mekanis terhadap pengarahan- pengarahan rutin organisasi. Sedangkan menurut 
Rauch \& Behling yang juga dikutip Rivai (2004), Kepemimpinan adalah proses mempengaruhi aktivitasaktivitas sebuah kelompok yang diorganisasi kearah pencapaian tujuan. Jacob \& Jacques dalam Rivai (2004) menyatakan kepemimpinan adalah suatu proses memberi arti (pengarahan yang berarti) terhadap usaha kolektif dan yang mengakibatkan kesediaan untuk melakukan usaha yang diinginkan untuk mencapai sasaran. Sudah menjadi tugas seorang pemimpin bahwa ia harus dapat mengutus dan memberdayakan bawahannya.

Menurut Chong and Law, (2016) mengutip sejumlah penelitian tentang perilaku psikologis dan organisasi juga memberikan dukungan teoritis dan empiris yang kuat untuk hubungan signifikan antara hubungan pimpinan-bawahan dan kinerja kerja (Cremer et al., 2001; Li and Tan, 2012; Zaheer et al., 1998). Individu dengan kepercayaan interpersonal yang tinggi dapat menghadapi dan menyelesaikan perselisihan pendapat (konfrontasi) yang mengurangi kejadian konflik selanjutnya akan menghasilkan hasil perilaku positif (kinerja pekerjaan yang lebih baik). Selanjutnya, Cremer et al. (2001) menunjukkan bahwa individu dengan kepercayaan lebih tinggi lebih bersedia berkontribusi daripada individu dengan kepercayaan rendah.

Li dan Tan (2012) mencatat bahwa bawahan yang memiliki tingkat kepercayaan yang tinggi pada supervisor/ atasan/ pimpinan tidak perlu mencurahkan sumber daya yang tidak perlu yang menyebabkan ketidakpastian yang dirasakan dalam konteks sosial dari tempat kerja. Studi non-akuntansi ini memberikan bukti pendukung bahwa pimpinan yang mendukung bawahan akan menerjemahkan ke kinerja pekerjaan yang lebih tinggi. Literatur yang dibahas menunjukkan bahwa ketika bawahan mempercayai atasan mereka maka lingkungan kerja akan menjadi lebih baik, yaitu suasana santai dan konflik yang jauh lebih sedikit, memunculkan kesediaan dan motivasi mereka untuk mengeluarkan energi ke pekerjaan lebih produktif. Oleh karena itu, karyawan lebih cenderung meningkatkan kinerja mereka bila mereka memiliki kepercayaan tinggi pada atasan mereka daripada bila mereka tidak melakukannya.

Sebuah komitmen merupakan hal yang penting untuk dijadikan ukuran karyawan untuk menuju kesuksesan perusahaan. Ketika kepuasan kerja karyawan meningkat, maka tingkat komitmen organisasi karyawan menjadi tinggi. Menurut Nijhof, De Jong dan Beukhof (1998), komitmen organisasi mengacu pada penerimaan nilai-nilai organisasi dan kesediaan untuk tinggal. Karyawan yang merasa puas menginginkan berada di tempat kerja yang sama, hal tersebut membuat komitmen meningkat, mengurangi keinginan untuk berpindah. dan dalam meningkatkan kinerja karyawan. Komitmen yang tinggi menjadikan individual peduli dengan nasib organisasi dan berusaha menjadikan organisasi kearah yang lebih baik. Dengan adanya komitmen yang tinggi kemungkinan penurunan kinerja dapat dihindari.

Komitmen

organisasi memegang peranan penting dalam meningkatkan kinerja karyawan. Tujuan dari komitmen organisasi 
adalah untuk memperbaiki kesalahankesalahan yang terjadi agar tidak terjadi terus menerus. Komitmen organisasi yang dijalankan dengan baik akan dapat meningkatkan prestasi dan disiplin kinerja dari para karyawan serta karyawan akan selalu bertanggung jawab terhadap pekerjaan yang dilaksanakan.

Penelitian ini bertujuan untuk meneliti Pengaruh Kepemimpinan Transformasional terhadap Kinerja Karyawan yang dimediasi oleh Kepercayaan Organisasional dan Komitmen Afektif di PT. Arpeni Pratama Ocean Line Tbk Cabang Jepara.

\section{TINJAUAN PUSTAKA}

\section{Kinerja Kerja Karyawan}

Muindi, dan K'Obonyo, (2015), Kinerja karyawan dapat didefinisikan dari perspektif perilaku atau hasil. Makanya, itu bisa dianggap sebagai konsep multi dimensi Campbell (1990) menggambarkan kinerja sebagai variabel tingkat individu yang membedakan kinerja karyawan dari kinerja organisasi. Ketika mengkonseptualisasikan kinerja karyawan, seseorang harus membedakan antara aspek perilaku tindakan dan aspek hasil kinerja. Aspek perilaku mengacu pada apa yang dilakukan seseorang dalam situasi kerja dan hubungannya dengan tujuan organisasi, sedangkan aspek outcome mengacu pada konsekuensi dan hasil perilaku individu dan dapat dipengaruhi oleh faktor lingkungan. Membedakan antara tugas dan kinerja kontekstual dan mengacu pada kinerja tugas sebagai kemampuan seseorang yang dengannya dia melakukan aktivitas yang berkontribusi secara langsung atau tidak langsung terhadap bidang teknis organisasi. Namun, kinerja kontekstual mengacu pada aktivitas yang tidak berkontribusi pada inti teknis, namun mendukung lingkungan organisasi, sosial, dan psikologis dimana tujuan organisasi dikejar. Kinerja tugas berbeda dari kinerja kontekstual dalam tiga cara.

Pertama, dalam kinerja tugas, kegiatan bervariasi antar pekerjaan, sedangkan dalam kondisi kontekstual, aktivitasnya serupa. Kedua, kinerja tugas berhubungan dengan kemampuan, sedangkan kinerja kontekstual berhubungan dengan kepribadian dan motivasi. Ketiga, kinerja tugas lebih diresepkan dan merupakan perilaku in-role, sedangkan kinerja kontekstual lebih discretionary dengan perilaku extra-role (Motowidlo \& Schmit, 1999). Campbell (1990) mengajukan delapan faktor model kinerja pekerjaan. Di antara delapan komponen kinerja yang diusulkan, lima faktor mengacu pada kinerja tugas termasuk kemampuan tugas spesifik pekerjaan, kemampuan tugas tidak spesifik pekerjaan, kemampuan tugas komunikasi tertulis dan lisan, pengawasan dalam hal posisi supervisor atau kepemimpinan, dan sebagian manajemen / administrasi. Selanjutnya, tiga faktor lainnya adalah faktor kontekstual seperti menunjukkan usaha, menjaga disiplin pribadi, dan memfasilitasi kinerja rekan kerja dan tim. Pada tingkat yang sangat umum, seseorang dapat membedakan 
antara dua jenis kinerja kontekstual: perilaku yang terutama melibatkan kelancaran fungsi organisasi seperti pada saat sekarang, dan perilaku proaktif yang bertujuan untuk mengubah dan memperbaiki prosedur kerja dan proses organisasi.

\section{Transformational Leadership} (TL)

Kepemimpinan

Transformasional telah mendapatkan perhatian besar peneliti dan telah diteliti lebih dari teori kepemimpinan lainnya. Periset juga telah mengeksplorasi efek kepemimpinan transformasional pada berbagai hasil terkait pekerjaan seperti komitmen dan kepercayaan (Sivasubramaniam, 1996). Satu hal yang telah menciptakan ketertarikan pada TL adalah hubungan efektif antara pemimpin dan pengikut mereka. Hal ini dibenarkan oleh banyak penelitian yang menunjukkan bahwa ada hubungan langsung dan positif antara pemimpin transformasional dan kinerja pengikut mereka (Boehke et al., 2003).

Kepemimpinan

Transformasional adalah proses yang mengkonseptualisasikan bagaimana pemimpin mampu menginspirasi pengikut mereka untuk menyelesaikan tugas mereka melebihi harapan. Pemimpin dipercaya dan dikagumi, dan diyakini memberdayakan karyawan untuk melampaui keterpusatan diri mereka sendiri demi kemajuan organisasi (Bass, 1995).

\section{Kepercayaan (Trust)}

Koohang, Alex,

Paliszkiewicz, Joanna,. and

Goluchowski, Jerzy. (2017) mengutip Sabel (1993) mendefinisikan kepercayaan sebagai kepercayaan antara dua pihak dengan pemahaman bahwa tidak ada pihak yang akan mengeksploitasi kerentanan orang lain. Kepercayaan menciptakan sebuah kesempatan untuk menghadapi kompleksitas dunia (Luhmann, 1979). Ini mewakili berapa banyak risiko yang bersedia kita terima sebagai imbalan atas manfaat dari interaksi dengan orang lain. Kepercayaan juga dipandang sebagai kecenderungan individu yang dapat bergantung pada orang lain untuk menyelesaikan tugas tanpa dipantau (Mayer et al., 1995).

\section{Komitmen (Commitment)}

Menurut Robbins (2001) komitmen pada organisasi didefinisikan sebagai suatu keadaan dimana seorang karyawan memihak pada suatu organisasi tertentu dan tujuan-tujuannya, serta berniat memelihara keanggotaan dalam organisasi itu. Komitmen pada organisasi yang tinggi berarti pemihakan pada organisasi yang mempekerjakannya. Bukti riset memperlihatkan hubungan negatif antara komitmen organisasi dengan kemangkiran maupun tingkat keluar masuknya karyawan (turnover).

\section{METODE PENELITIAN}

Metode yang digunakan adalah penelitian survey dengan jenis penelitian penjelasan (explanatory) 
dengan studi khalayak, menurut Singarimbun dan Effendy (2006:4-5), "Penelitian penjelasan yang dimaksud untuk menyoroti hubungan antar variabel dan menguji hipotesis yang telah dirumuskan".

Sampel minimum yang disarankan dalam penggunaan SEM berbasis covariance adalah lebih dari 100 (metode terendah yaitu maximum likelihood yang mensyaratkan sampel minimum 100-200) atau minimal 510 kali jumlah observasi (Ferdinand, 2006:49). Sampel minimum (>100) dan yang direkomendasikan untuk parameter atau indikator sejumlah dikali 5- 10, tidak terpenuhi karena jumlah seluruh karyawan hanya 58 orang $(<100)$.

Maka syarat kecukupan sampel tidak terpenuhi atau jumlah sampel tidak memenuhi syarat pengambilan sampel minimum SEM parametrik (Covariance Based SEM) maka penelitian tidak dapat dilanjutkan menggunakan alat analisis statistik SEM parametrik (Covariance Based SEM). Teknik pengambilan sampel yang digunakan dalam penelitian ini adalah dengan metode sensus, yaitu pengambilan sampel dengan mengambil seluruh jumlah populasi yang ada dengan jumlah 58 orang responden.

Keterbatasan sampel penelitian maka pengujian dalam penelitian ini, maka analisis akan dilanjutkan menggunakan alat analisis statistik SEM non-parametrik atau dikenal SEM berbasis komponen (Component Based SEM), yang merupakan alternatif dari Covariance Based SEM atau SEM Parametrik (Ghozali, 2008:4). Adapun alat analisis yang akan digunakan menggunakan bantuan program GSCA (Generalized
Structured Component Analysis) salah satu program/ software pengujian SEM berbasis komponen.

\section{HASIL PENELITIAN}

Pengujian analisis hipotesis dilakukan menggunakan metode Structural Equation Modeling (SEM), dengan terlebih dahulu dianalisis menggunakan aplikasi AMOS (salah satu aplikasi SEM berbasis covariance atau covariance based $S E M$ ) yang bersifat parametrik, dan hasil menunjukkan bahwa salah satu syarat lolos pengujian tidak terpenuhi (data tidak terdistribusi normal) maka pengujian hipotesis dilanjutkan menggunakan bantuan SEM berbasis component atau variance (Component Based SEM) yang bersifat nonparametrik, yaitu: Generalized Structured Component Analysis (GSCA).

Sebagai alternatif covariance based SEM, pendekatan variance based atau component based dengan GSCA orientasi analisis bergeser dari menguji model kausalitas/teori ke component based predictive model (prediksi). Hasil pengujian hipotesis dalam penelitian menggunakan aplikasi GSCA.

Hasil Pengujian kualitas intrumen (indikator variabel) penelitian meliputi uji validitas dan reliabilitas (validity \& reliability), menunjukkan bahwa tiap item pada masing-masing variabel dinyatakan valid karena memiliki nilai loading > 0,5 baik pada loading, weight, maupun SMC (Squared Multiple Correlation). Hal tersebut menunjukkan bahwa tiap item dapat mengukur variabel yang diteliti.

Hasil pengujian reliabilitas 
yang meliputi uji reliabilitas Cronbach Alpha dan AVE (Average Variance Extracted). Nilai Cronbach Alpha dan nilai reliabilitas AVE pada tiap variabel $>0,50$ (Kriteria Nunnally, 1960 dalam Ghozali,
2006), maka seluruh variabel dinyatakan handal (reliabel).

Penerapan hasil analisis pada model penelitian selengkapnya dapat di lihat pada gambar di bawah ini:

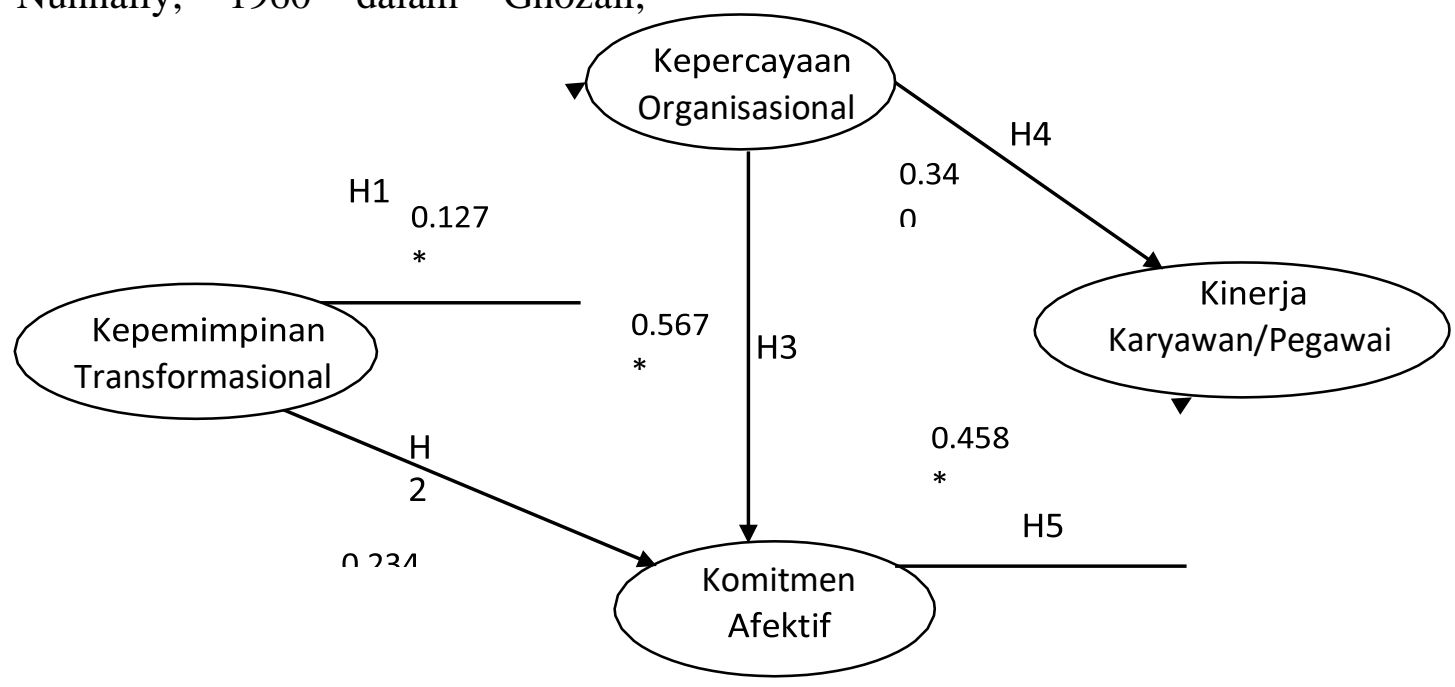

Gambar 1. Hasil Analisis Data Pengujian Struktural

Keterangan:

*= Berpengaruh pada level signifikansi 0,05 (5\%)

\section{KESIMPULAN DAN SARAN}

Temuan

menunjukkan

kepemimpinan hasil bahwa transformasional berpengaruh signifikan secara langsung terhadap tingkat kepercayaan organisasional. Hal ini menunjukkan bahwa kepemimpinan transformasional merupakan variabel yang dianggap penting dalam meningkatkan tingkat kepercayaan organisasional. Semakin tinggi kepemimpinan transformasional maka dapat meningkatkan tingkat kepercayaan organisasional, dan begitupun sebaliknya, semakin rendah kepemimpinan transformasional belum tentu menurunkan tingkat kepercayaan organisasional.

Kepemimpinan

transformasional tidakberpengaruh signifikan positif terhadap komitmen afektif, hal tersebut tidak sejalan dengan teori dan temuan penelitian yang menyatakan bahwa kepemimpinan transformasional memiliki pengaruh signifikan positif terhadap komitmen organisasi. Selain itu banyak temuan lainnya yang terungkap. Kepemimpinan transformasional memiliki pengaruh positif terhadap kinerja karyawan tetapi tidak pada kepuasan kerja. Komitmen organisasi ditemukan memiliki pengaruh signifikan terhadap kepuasan kerja dan kinerja karyawan. Penelitian ini menekankan pada para pemimpin untuk mengembangkan keterampilan kepemimpinan transformasional untuk menumbuhkan komitmen organisasi dari tatanan untuk 
menumbuhkan komitmen organisasi (Jain and Duggal, 2016).

Tingkat

kepercayaan

organisasional tinggi maka akan semakin meningkatkan tingkat komitmen afektif karyawan pada organisasi. Kepercayaan atas organisasi akan menumbuhkan tingkat komitmen karyawan pada organisasi tersebut. Tingginya tingkat komitmen karyawan maka akan diiringi oleh peningkatan kinerja mereka saat melaksanakan tugas kerja. Hal ini akan berbanding terbalik dengan tingkat kepercayaan yang rendah maka akan ditunjukkan oleh komitmen mereka dalam bekerja yang rendah serta kinerja mereka cenderung bermalas-malasan atau bekerja biasa- biasa saja hanya untuk memenuhi tugas mereka, bahkan pada tingkat yang lebih parah akan ditunjukkan oleh kebiasaan terlambat datang kerja atau pulang lebih awal dari jam pulang kerja.

\section{DAFTAR PUSTAKA}

Anderson, E. and Weitz, B. (1992), "The use of pledges to build and sustain commitment in distribution channels", Journal of Marketing Research, Vol. 29 No. 1, pp. 18-34.

Arnold, A.E., Maynard, Z., Gilbert, G.S., Coley, P.D. and Kursar, T.A. (2000), "Are tropical fungal endophytes hiperdiverse?", Ecology Letters, Vol. 3 No. 4, pp. 267274.

Attari, Maryam. 2013. The Impact of Transformational Leadership on Nurse Psychological Empowerment. International Journal of Hospital Research 2013, 2(2):71-76.
Avolio, B.J. (2003), "Examining the full range model of leadership: looking back to transform forward", in Day,

D. and Zaccarro, S. (Eds), Leadership Development for Transforming Organisations: Grow Leaders for Tomorrow, Lawrence Erlbaum Associates, Mahwah, NJ, pp. 71-98

Baek-Kyoo, J. and Ji, H.S. (2010), "Psychological empowerment and organisational commitment: the moderating effect of organisational learning culture", Human Resource Development International, Vol. 13 No. 4, pp. 425-441.

Bass, B.M. (1995), "Theory of transformational leadership redux", Leadership Quarterly, Vol. 6 No. 4, pp. 463-478.

Bass, B.M. (1998), Transformational Leadership: Industry, Military, and Educational Impact, Erlbaum, Mahwah, NJ.

Bennis, W. and Nanus, B. (1985), Leadership: The Strategies for Taking Charge, Harper \& Row, New York, NY.

Betty Chiu, Wai Yee, and Fai Ng, Fung. 2015. Enhancement of organizational commitment through propensity to trust. Engineering, Construction and Architectural Management. Vol. 22 No. 3, 2015. pp. 272294.

Brief, A. and Nord, W. (1990), "Work and meaning: definitions and interpretations", in Brief, A. and Nord, W. (Eds), The Meaning of Occupational Work, Lexington, Lexington, MA, pp. 1-20. 
Burns, J.M. (1978), Leadership, Harper and Row, New York, NY.

Davis, J.H. and Mayer, R.C. (1995), "An integrative model of organisational trust", Academy of Manage Review, Vol. 20 No. 3, pp. 709-734.

Deci, E.L. and Ryan, R.M. (1987), "The support of autonomy and the control of behavior", Journal of Personality and Social Psychology, Vol. 53 No. 6, pp. 1024-1103.

Dirks, K.T., Kim, P.H., Ferrin, D.L. and Cooper,

C.D.

(2011),

"Understanding the effects of substantive responses on trust following a transgression", Organisational Behaviour and Human Decision Processes, Vol. 114 No. 2, pp. 87-103.

Goodwin, V.L., Whittington, J.L., Murray, B. and Nichols, T. (2011), "Moderator or mediator? Examining the role of trust in the transformational leadership paradigm", Journal of Managerial Issues, Vol. 23 No. 4, pp. 409-425.

Judge, T.A. and Piccolo, R.F. (2004), "Transformational and transactional leadership: a meta analytic test of their relative validity", Journal of Applied Psychology, Vol. 89 No. 5,pp. 755-768.

Kelloway, E.K., Turner, N., Barling, J. and Loughlin, C. (2012),

"Transformational leadership and employee psychological well-being: the mediating role of employee trust in leadership", Work and Stress, Vol. 26 No. 1, pp. 39-55.

Koohang, Alex,. Paliszkiewicz, Joanna,. and Goluchowski, Jerzy. 2017. The impact of leadership on trust, knowledge management, and organizational performance: A research model. Industrial Management \& Data Systems. Vol. 117 No. 3, 2017. pp. 521537.

Liden, R.C., Wayne, S.J. and Sparrowe, R.T. (2000), "An examination of the mediating role of psychological empowerment on the relations between the job, interpersonal relationships, and work outcomes", Journal of Applied Psychology, Vol. 85 No. 5, pp. 407-416.

Liu, C.H., Chang, L.C., Li, I.C., Liao, J.Y. and Lin, C.I. (2006), "Organisational and psychological empowerment on organisational commitment and job satisfaction among primary health professionals", Journal of Evidence- Based Nursing, Vol. 2 No. 1, pp. 5-13.

Liu, M.M.A., Chiu, W.M. and Fellows, R. (2007), "Enhancing commitment through work empowerment", Engineering, Construction and Architectural Management, Vol. 14 No. 6, pp. 568-580.

Lowe, K.B., Kroeck, K.G. and Sivasubramaniam, N. (1996), "Effectiveness correlates of transformational and transactional leadership: a meta-analytic review of the MLQ literature", Leadership 
Quarterly, Vol. 7 No. 3, pp. 385-425

McAllister, D.J. (1995), “Affect- and cognition-based trust as foundations for interpersonal cooperation in organisations", Academy of Management Journal, Vol. 38 No. 1,pp. 2459.

Menon, S.T. (2001), "Employee empowerment: an integrative psychological approach", Applied Psychology: An International Review, Vol. 50 No. 1, pp. 153-180

Mittal, Swati. 2015. Effects of transformational leadership on turnover intentions in IT SMEs. International Journal of Manpower. Vol. 37 No. 8, 2016. pp. 1322-1346.

Piccolo, R.F. and Colquitt, J.A. (2006), "Transformational leadership and job behaviors: the mediating role of job characteristics", Academy of Management Journal, Vol. 49 No. 2, pp. 327-340.

Podsakoff, P.M., MacKenzie, S.B., Lee, J.Y. and Podsakoff, N.P. (2003), "Common method biases in behavioural research: a critical review of the literature and recommended remedies", Journal of Applied Psychology, Vol. 88 No. 5, pp. 879-903.

Podsakoff, P.M., MacKenzie, S.B., Lee, J.Y. and Podsakoff, N.P. (2003), "Common method biases in behavioural research: a critical review of the literature and recommended remedies", Journal of Applied Psychology, Vol. 88 No. 5, pp. 879-903.

Podsakoff, P.M., MacKenzie, S.B., Moorman, R.H. and Fetter, R.
(1990), “Transformational leader behaviors and their effects on followers' trust in leader, satisfaction, and organisational citizenship behavior", The Leadership Quarterly, Vol. 1 No. 2, pp. 107-142.

Podsakoff, P.M., MacKenzie, S.B., Moorman, R.H. and Fetter, R. (1990), "Transformational leader behaviors and their effects on followers' trust in leader, satisfaction, and organisational citizenship behavior", The Leadership Quarterly, Vol. 1 No. 2, pp. 107-142.

Postmes, T., Tanis, M. and de Wit, B. (2001), "Communication and commitment in organisations: a social identity approach", Group Processes and Intergroup Relations, Vol. 4 No. 3, pp. 227-246.

Rafferty, A.E. and Griffin, M.A. (2004), "Dimensions of transformational leadership: conceptual and empirical extensions", The Leadership Quarterly, Vol. 15 No. 3, pp. 329-354.

Raju, G.A. and Kurpad, M. (2013), "SME securitization: a new ray of hope for SMEs in India", The Journal of Structured Finance, Vol. 19 No. 2, pp. 89-119.

Randolph, W.A. (2000), "Re-thinking empowerment: why is it so hard to achieve?",Organisational Dynamics, Vol. 29 No. 2, pp. 94-107

Rivai, V. 2004. Kepemimpinan dan Perilaku Organisasi. Jakarta: Raja Grafindo Persada. 
Spreitzer, G.M. (1995), "Psychological empowerment in the workplace: dimensions, measurement and validation", Acad emy of

Management Journal, Vol. 38 No. 5, pp. 1442-1465.

Vacharakiat, M. (2008), "The relationships of empowerment, job satisfaction, and organisational commitment among Filipino and Americanregistered nurses working in the USA", $\mathrm{PhD}$, University of George, Mason.

Wong, Yui-tim,. Wong, Yui-Woon,. and Wong, Chi-sum. 2015. An integrative model of turnover intention Antecedents and their effects on employee performance in Chinese joint ventures. Journal of Chinese Human Resource Management. Vol. 6 No. 1, 2015. pp. 71-90.
Yu, Yanni and Choi, Yongrok. 2014. Corporate social responsibility and firm performance through the mediating effect of organizational trust in Chinese frms. Chinese Management Studies. Vol. 8 No. 4, 2014. pp. 577-592.

Zeffane, R., Zarooni, A. and Mohammed, H.A. (2012), "Empowerment, trust and commitment: the moderating role of work-unit centrality", International Journal of Management, Vol. 29 No. 1, pp. 332-351.

Jain, Priyanka., and Duggal, Taranjeet. 2016. Transformational leadership and organizational commitment: Testing the moderating role of Emotional intelligence in Indian IT sector. BVIMSR's Journal of Management Research. Vol. 8 Issue- 2: October : 2016. 